\title{
Origins of Contrasteric $\pi$-Facial Selectivity in Epoxidations of Encumbered Tetrahydropyridines by a Bifunctional Peracid
}

\author{
Shuming Chen* ${ }^{*}$ \\ Sining Wang \\ K. N. Houk* (1)
}

Department of Chemistry and Biochemistry, University of California, Los Angeles, California 90095-1569, USA

shuming@chem.ucla.edu

houk@chem.ucla.edu

Published as part of the 30 Years SYNLETT - Pearl Anniversary Issue
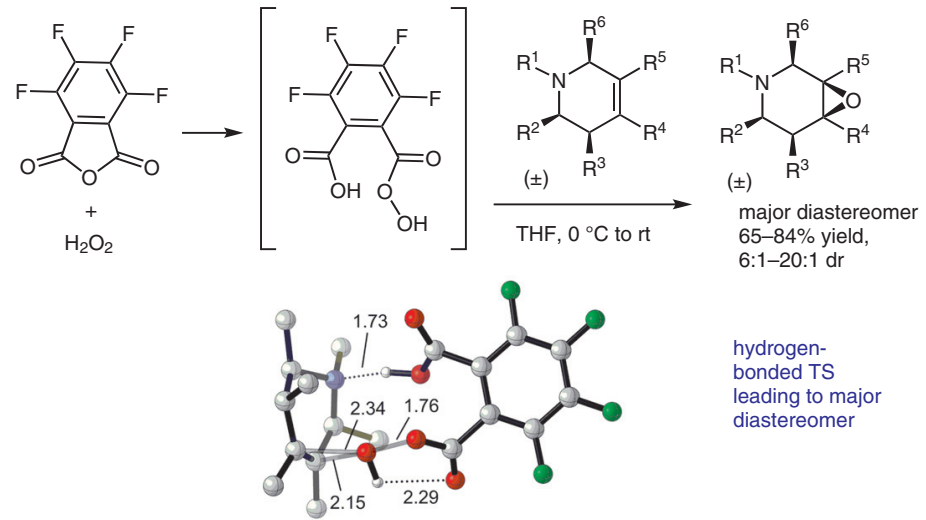

$6: 1-20: 1 \mathrm{dr}$

hydrogen-

bonded TS

leading to major

diastereomer
Received: 01.12.2018

Accepted after revision: 21.01.2019

Published online: 25.01 .2019

DOI: 10.1055/s-0037-1611674; Art ID: st-2018-b0781-I

License terms: cc)

Abstract The origins of contrasteric diastereoselectivity in the epoxidation of encumbered tetrahydropyridines have been elucidated via density functional theory (DFT) calculations. A strong energetic preference for $\mathrm{OH} \cdots \mathrm{N}$ hydrogen bonding was found for epoxidation transition states of the unsubstituted tetrahydropyridine. For hexasubstituted tetrahydropyridines, the diastereofacial selectivity is dictated by both the strong $\mathrm{OH} \cdots \mathrm{N}$ hydrogen bonding and the conformational preference of the tetrahydropyridine substrate.

Key words DFT calculation, heterocycles, piperidines, epoxidation, stereoselective synthesis

Nitrogen heterocycles are prevalent motifs in natural products and pharmaceutical agents that constitute important synthetic targets for drug discovery. ${ }^{1,2}$ Efficient methods of accessing functionalized nitrogen heterocycles with high levels of stereocontrol are therefore highly sought after. $^{3}$ The ability of hydroxyl groups to direct the stereoselectivity of alkene epoxidations through hydrogen-bonding interactions has been well-documented and investigated., ${ }^{4,5}$ The role of torsional effects ('torsional steering') has also been established for epoxidations and related oxidations. ${ }^{6}$ Although examples of stereoselective epoxidations have been reported that are hypothesized to be directed by nitrogen-containing groups, ${ }^{7}$ no computational studies have aimed to elucidate the origins of these selectivities. ${ }^{8}$

In an effort to access multiple functionalized piperidines, the Ellman group ${ }^{9}$ sought to exploit the hydrogenbonding ability of nitrogen-containing groups to enforce the diastereoselective epoxidation of tetrahydropyridines $\mathbf{3}$ (Scheme 1, a). The experimental protocol involves the treatment of tetrafluorophthalic anhydride $\mathbf{1}$ with hydrogen peroxide to yield bifunctional epoxidation agent $\mathbf{2}$. In addition to the oxidizing peracid functionality, $\mathbf{2}$ also possesses a carboxylic acid group capable of forming strong hydrogen bonds with the basic amine nitrogen in $\mathbf{3}$ either before or after proton transfer. It was hypothesized that the tetrafluoroarene portion serves as a rigid covalent tether, forcing the epoxidation event to occur at the hydrogen-bonded $\pi$-face of the molecule. Interestingly, for tetrahydropyridines $\mathbf{3}$, contrasteric delivery of the epoxide oxygen to the more hindered $\pi$-face is observed (Scheme 1, b). Epoxidation agents without the tether feature, such as $m$-CPBA and trifluoroperacetic acid, resulted in low diastereoselectivities (Scheme 1, a).

Given this remarkable ability of this transformation to override steric bias, we undertook a computational investigation into the origins of diastereoselectivity for the epoxidation of tetrahydropyridines shown in Scheme 1 (a).

Computations were performed with Gaussian 09. ${ }^{10}$ Molecular geometries were optimized using the M06-2X ${ }^{11}$ functional and the $6-31+G(d)$ basis set. The effect of solvation on molecular geometries was accounted for during optimizations using the $\mathrm{SMD}^{12}$ solvation model with tetrahydrofuran as the solvent. Frequency calculations were carried out at the same level of theory as that used for geometry optimization to characterize the stationary points as either minima (no imaginary frequencies) or saddle points (one imaginary frequency) on the potential energy surface and to obtain thermal corrections to the Gibbs free energies. Intrinsic reaction coordinate (IRC) calculations were performed to ensure that the saddle points found were true transition states connecting the reactants and the products. Single-point energies were calculated with the M06-2X functional and the $6-311++G(3 \mathrm{df}, 2 \mathrm{pd})$ basis set, and solvation effects were modeled using the SMD solvation model with tetrahydrofuran as the solvent. For fragment distortion analysis, single-point energies of the 


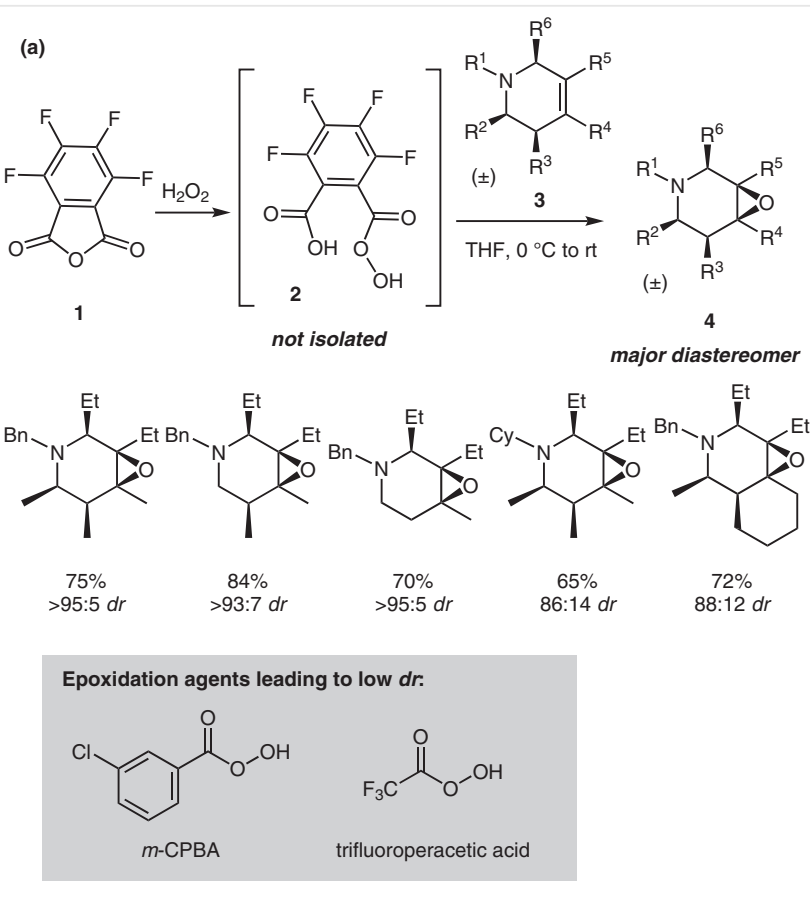

(b)

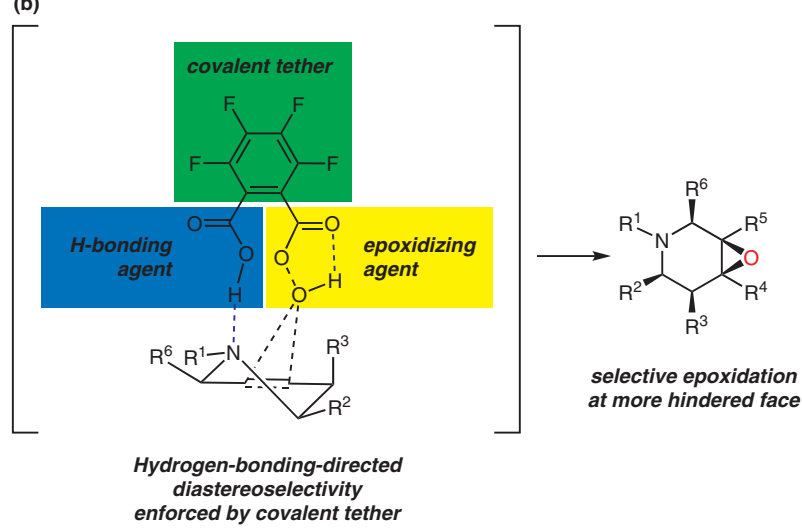

Scheme 1 (a) Diastereoselective epoxidations of tetrahydropyridines 3 by the in situ generated bifunctional epoxidation agent 2-carboperoxy3,4,5,6-tetrafluorobenzoic acid (2). (b) Design principle of the bifunctional epoxidation agent $\mathbf{2}$.

molecular fragments were computed at the M06-2X/6$311++G(3 d f, 2 p d)$ level using the M06-2X/6-31+G(d) geometries obtained in solution. Molecular structures were visualized using CYLview. ${ }^{13}$ Monte Carlo conformational searches were performed with the Merck molecular force field (MMFF) implemented in Spartan '16 to ensure that the lowest energy conformations of intermediates and transition states are presented in the manuscript. Geometries and energies of alternative conformers explored in this study can be found in the Supporting Information.

We first calculated the hydrogen-bonded and nonhydrogen-bonded epoxidation transition states for the epoxidation of unsubstituted 1,2,5,6-tetrahydropyridine 3a by 2
(Scheme 2, a). A free energy preference of $3.8 \mathrm{kcal} / \mathrm{mol}$ was found in favor of the hydrogen-bonded transition state TS$\mathbf{1}$, in which the $\mathrm{O}-\mathrm{H} \cdot \mathrm{N}$ N distance is $1.73 \AA$ (Scheme 2 , b). The strong preference for a hydrogen-bonded TS is particularly striking considering that the hydrogen bond has the effect of deactivating the alkene double bond toward electrophilic epoxidation by making the alkene moiety less nucleophilic.

(a)

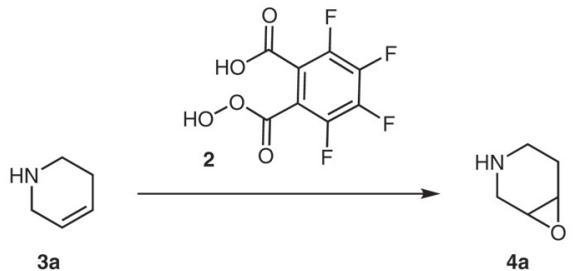

(b)
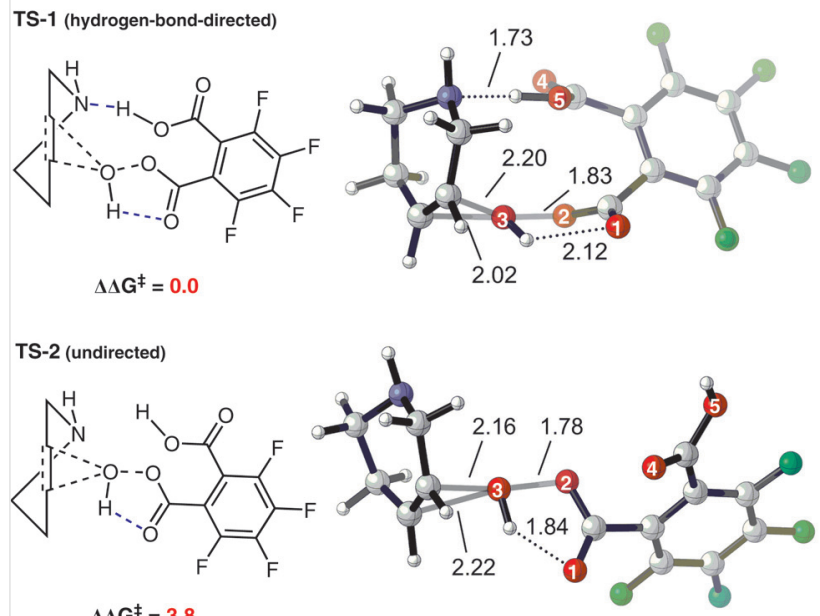

$\Delta \Delta G^{\ddagger}=3.8$

(c)
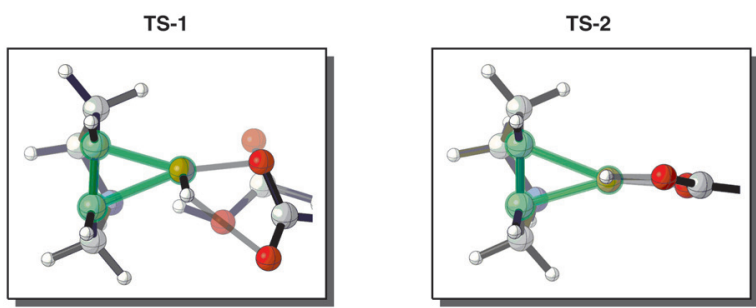

Scheme 2 (a) Epoxidation of 3 a by bifunctional agent 2. (b) Calculated transition states for the epoxidation of $\mathbf{3} \mathbf{a}$ by $\mathbf{2}$. Energies are denoted in $\mathrm{kcal} / \mathrm{mol}$, and interatomic distances are shown in Ångströms. (c) Sideon view of TS-1 and TS- $\mathbf{2}$ showing alignment of the peracid and alkene moieties.

Examination of TS-1 and TS-2 reveals several important geometrical consequences of the hydrogen bonding. In the absence of a hydrogen bond, the peracid and the alkene in TS-2 assumes the expected spiro geometry (Scheme 2, c), which maximizes the stabilizing secondary orbital interaction between the oxygen lone pair and the alkene $\pi^{*}$ orbital. ${ }^{14}$ This interaction is weaker in TS-1, presumably because 
a spiro geometry cannot be achieved due to geometrical constraints imposed by the hydrogen bond. The same geometrical constraints also force the peracid moiety to adopt a nonplanar arrangement. This nonplanarity weakens the hydrogen bond between 01 and the peracid proton $(2.12 \AA$, compared to $1.84 \AA$ in TS-2). In TS-2, the formation of the two $\mathrm{C}-\mathrm{O}$ bonds is only slightly asynchronous at 2.16 and 2.22 Å, respectively, whereas TS-1 is much more unsymmetrical ( 2.20 and $2.02 \AA$ ).

Having established the favorability of the hydrogenbonded TS, we next investigated the epoxidation of hexasubstituted tetrahydropyridine scaffolds, represented by tetrahydropyridine $\mathbf{1 b}$. These tetrahydropyridines are observed to undergo epoxidation at the more sterically encumbered $\pi$-face.

Computed transition states for the epoxidation of $\mathbf{3 b}$ by $\mathbf{2}$ are shown in Scheme 3. For each product diastereomer, a hydrogen-bonded TS and a nonhydrogen-bonded TS can be envisioned. For TS-4 and TS-6, the two transition states without $\mathrm{OH}$... $\mathrm{N}$ hydrogen bonding, calculated free energies of activation indicate that the reaction should be 2.0 $\mathrm{kcal} / \mathrm{mol}$ in favor of epoxidation at the less sterically hindered face. With $\mathrm{OH}$... N hydrogen bonding, however, the preference is $7.1 \mathrm{kcal} / \mathrm{mol}$ in favor of contrasteric epoxidation (TS-3 and TS-5). Geometrically, the undirected transition states TS-4 and TS-6 are spiro and highly symmetrical, similar to TS-2. The hydrogen-bonded TS-3 and TS-5 are both distorted away from a spiro geometry, with highly asynchronous formation of the two $\mathrm{C}-\mathrm{O}$ bonds. Overall, the hydrogen-bonded TS-3 is $1.7 \mathrm{kcal} / \mathrm{mol}$ lower in energy than TS-6, which explains the experimentally observed selectivity for diastereomer $\mathbf{4 b} \mathbf{b}$. This result confirms that the $\mathrm{OH}$... N hydrogen bond is strong enough to override the effects of steric congestion. Considering that the amine moiety is likely to be partially protonated under reaction conditions, which would deactivate the $\mathrm{C}=\mathrm{C}$ bond toward electrophilic epoxidation, undirected epoxidation is likely to have barriers that are higher than those calculated for TS-4 and TS-6, as these transition states do not take the effect of amine protonation into account.

To further explain the severe energetic unfavorability of TS-5, we calculated the distortion energies $\left(\mathrm{E}_{\mathrm{dist}}{ }^{\ddagger}\right)$ of the tetrahydropyridine fragment in epoxidation transition states TS 3-6 (Figure 1). These $\mathrm{E}_{\text {dist }}^{\ddagger}{ }^{\ddagger}$ values are obtained by comparing gas-phase electronic energies of transition-state geometries of the tetrahydropyridine to that of the corresponding ground-state geometry. ${ }^{15}$ The tetrahydropyridine fragment in TS-5 has a high $\mathrm{E}_{\mathrm{dist}}{ }^{\ddagger}$ value of $13.6 \mathrm{kcal} / \mathrm{mol}$, which is $8.8 \mathrm{kcal} / \mathrm{mol}$ higher than the corresponding $\mathrm{E}_{\mathrm{dist}}{ }^{\ddagger}$ value in TS-3. This difference in distortion energy is comparable in magnitude to the $\Delta \Delta \mathrm{G}^{\ddagger}$ value of $7.1 \mathrm{kcal} / \mathrm{mol}$ between TS-3 and TS-5, indicating that the free energy distinction can be mostly attributed to the distortion of the tetrahydropyridine substrate. Geometrically, the tetrahy- dropyridine fragment in $\mathbf{T S}-\mathbf{5}$ is deformed into a twistboat-like structure to allow the nitrogen lone pair to occupy the pseudo-axial position needed for hydrogen bonding. Unfavorable near-eclipsing interactions in the twist-boatlike structure (Figure 1 ) result in a high $\mathrm{E}_{\text {dist }}{ }^{\ddagger}$ value.

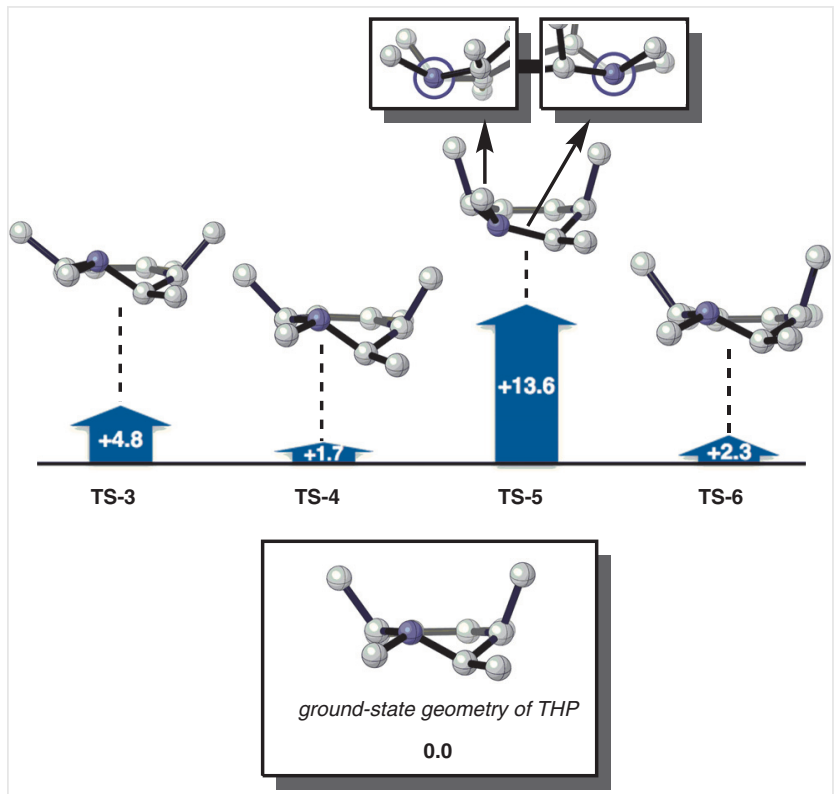

Figure 1 Geometries of the tetrahydropyridine fragment in epoxidation transition states TS-3-6, and distortion energies compared to the ground-state reactant. Newman projection insets show near-eclipsing interactions between ring substituents. Energies are denoted in $\mathrm{kcal} / \mathrm{mol}$. Hydrogen atoms are omitted for clarity.

In conclusion, we used DFT calculations to reveal the origins of the contrasteric $\pi$-facial stereoselectivity in the epoxidation of densely substituted tetrahydropyridines by a bifunctional peracid reagent 2 . We show that epoxidation of 1,2,3,6-tetrahydropyridines with $\mathbf{2}$ have a strong preference to proceed through $\mathrm{OH}$... $\mathrm{N}$ hydrogen-bonded transition states. Even for hexasubstituted tetrahydropyridines that are highly congested at one $\pi$-face, the $\mathrm{OH}$... N hydrogen-bonding interaction is strong enough to overcome the steric disadvantage and deliver the contrasteric epoxide product.

\section{Funding Information}

This work was supported by the National Science Foundation (Grant CHE-1059084 to K. N. H.). XSEDE is supported by the National Science Foundation (Grant OCI-1053575).

\section{Acknowledgment}

Calculations were performed on the Hoffman2 cluster at the University of California, Los Angeles, and the Extreme Science and Engineering Discovery Environment (XSEDE). 


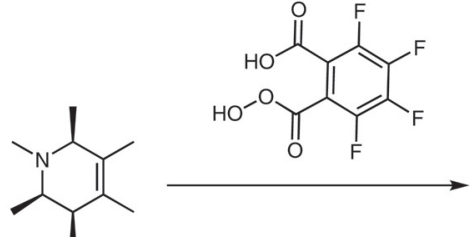

$3 b$

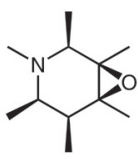

$4 b-A$

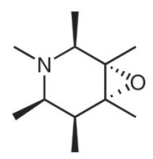

4b-B

(via TS-3 or TS-4) (via TS-5 or TS-6)

TS-3 (hydrogen-bond-directed)

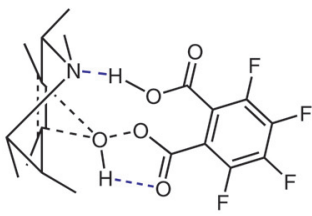

$\Delta \Delta G^{\ddagger}=0.0$

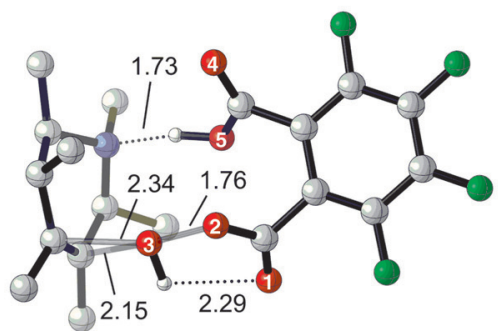

TS-4 (undirected)

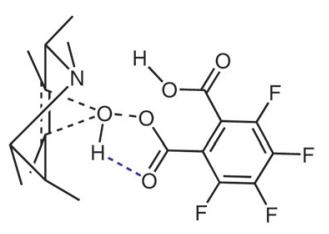

$\Delta \Delta \mathrm{G}^{\ddagger}=+3.7$

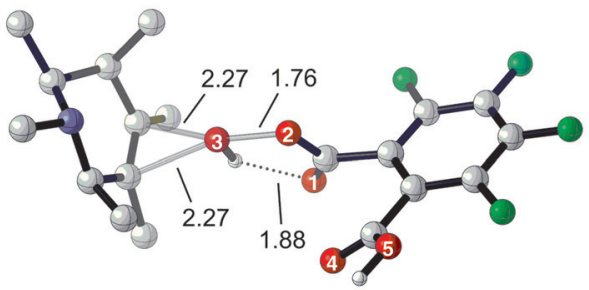

TS-5 (hydrogen-bond-directed)

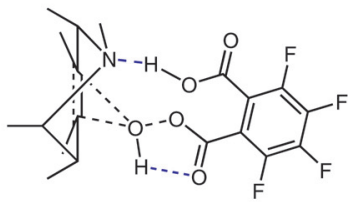

$\Delta \Delta \mathbf{G}^{\ddagger}=+7.1$

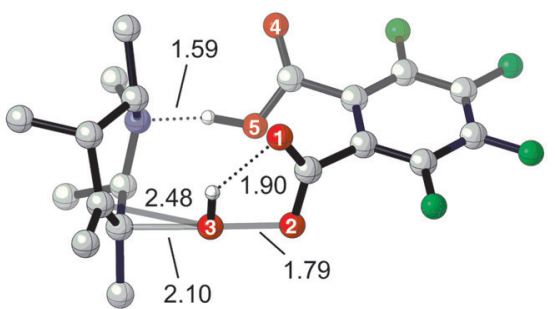

TS-6 (undirected)

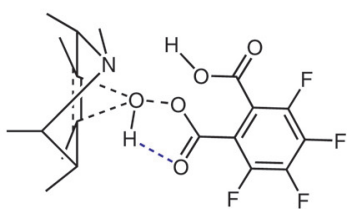

$\Delta \Delta \mathrm{G}^{\ddagger}=+1.7$

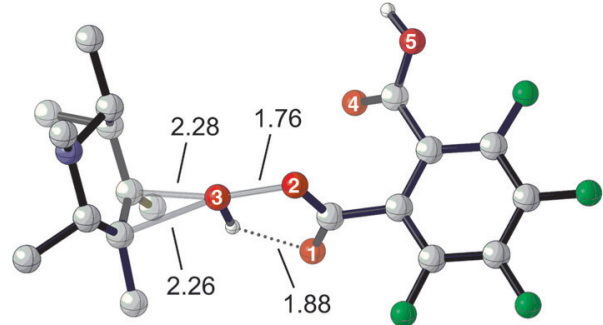

Scheme 3 Four calculated transition states for the epoxidation of $\mathbf{3 b}$ by $\mathbf{2}$. Energies are denoted in $\mathrm{kcal} / \mathrm{mol}$, and interatomic distances are shown in Ångströms. Hydrogen atoms attached to carbons are omitted for clarity. 


\section{Supporting Information}

Supporting information for this article is available online at https://doi.org/10.1055/s-0037-1611674.

\section{References and Notes}

(1) Roughley, S. D.; Jordan, A. M. J. Med. Chem. 2011, For an analysis of the prevalence of nitrogen heterocycles in pharmaceuticals, see: 54,3451 .

(2) For perspectives on nonplanar nitrogen heterocycles in drug discovery, see: (a) Lovering, F.; Bikker, J.; Humblet, C. J. Med. Chem. 2009, 52, 6752. (b) Walters, W. P.; Green, J.; Weiss, J. R.; Murcko, M. A. J. Med. Chem. 2011, 54, 6405. (c) Ritchie, T. J.; Macdonald, S. J. F. Drug Discovery Today 2009, 14, 1011.

(3) For recent examples of stereoselective nitrogen heterocycle synthesis, see: (a) Huang, X.; Li, X.; Xie, X.; Harms, K.; Riedel, R.; Meggers, E. Nat. Commun. 2017, 8, 2245. (b) Feng, J.-J.; Lin, T.-Y.; Zhu, C.-Z.; Wang, H.; Wu, H.-H.; Zhang, J.J. Am. Chem. Soc. 2016, 138, 2178. (c) Munnuri, S.; Adebesin, A. M.; Paudyal, M. P.; Yousufuddin, M.; Dalipe, A.; Falck, J. R. J. Am. Chem. Soc. 2017, 139, 18288. (d) Tait, M. B.; Butterworth, S.; Clayden, J. Org. Lett. 2015, 17, 1236. (e) Ballete, R.; Perez, M.; Proto, S.; Amat, M.; Bosch, J. Angew. Chem. Int. Ed. 2014, 53, 6202. (f) Duttwyler, S.; Chen, S.; Takase, M. K.; Wiberg, K. B.; Bergman, R. G.; Ellman, J. A. Science 2013, 339, 678. (g) Duttwyler, S.; Chen, S.; Lu, C.; Mercado, B. Q.; Bergman, R. G.; Ellman, J. A. Angew. Chem. Int. Ed. 2014, 53, 3877. (h) Chen, S.; Bacauanu, V.; Knecht, T.; Mercado, B. Q.; Bergman, R. G.; Ellman, J. A. J. Am. Chem. Soc. 2016, 138, 12664.

(4) Hoveyda, A. H.; Evans, D. A.; Fu, G. C. Chem. Rev. 1993, For a review of substrate-directed reactions, see: 93, 1307.

(5) For computational studies on hydroxyl-directed epoxidations, see: (a) Bach, R. D.; Estevez, C. M.; Winter, J. E.; Glukhovtsev, M. N. J. Am. Chem. Soc. 1998, 120, 680. (b) Adam, W.; Bach, R. D.; Dmitrenko, O.; Saha-Moeller, C. R. J. Org. Chem. 2000, 65, 6715. (c) Freccero, M.; Gandolfi, R.; Sarzi-Amade, M.; Rastelli, A.J. Org. Chem. 1999, 64, 3853. (d) Freccero, M.; Gandolfi, R.; SarziAmade, M.; Rastelli, A. J. Org. Chem. 2000, 65, 2030. (e) Freccero, M.; Gandolfi, R.; Sarzi-Amade, M.; Rastelli, A. J. Org. Chem. 2000, 65, 8948.

(6) (a) Cheong, P. H.-Y.; Yun, H.; Danishefsky, S. J.; Houk, K. N. Org. Lett. 2006, 8, 1513. (b) Wang, H.; Kohler, P.; Overman, L. E.; Houk, K. N. J. Am. Chem. Soc. 2012, 134, 16054.

(7) For recent examples, see: (a) Aggarwal, V. K.; Fang, G. Y. Chem. Commun. 2005, 3448. (b) Grishina, G. V.; Borisenko, A. A.; Veselov, I. S.; Petrenko, A. M. Russ. J. Org. Chem. 2005, 41, 272. (c) Brennan, M. B.; Claridge, T. D. W.; Compton, R. G.; Davies, S. G.; Fletcher, A. M.; Henstridge, M. C.; Hewings, D. S.; Kurosawa, W.; Lee, J. A.; Roberts, P. M.; Schoonen, A. K.; Thomson, J. E. J. Org. Chem. 2012, 77, 7241. (d) Brennan, M. B.; Davies, S. G.; Fletcher, A. M.; Lee, J. A.; Roberts, P. M.; Russell, A. J.; Thomson, J. E. Aust. J. Chem. 2015, 68, 610. (e) Da Silva, Pinto. S.; Davies, S. G.; Fletcher, A. M.; Roberts, P. M.; Thomson, J. E. Synthesis 2018, 50, 64. (f) Brambilla, M.; Brennan, M. B.; Csatayová, K.; Davies, S. G.; Fletcher, A. M.; Kennett, A. M. R.; Lee, J. A.; Roberts, P. M.; Russell, A. J.; Thomson, J. E. J. Org. Chem. 2017, 82, 10297.

(8) For kinetic studies on stereoselective oxidations of olefins directed by nitrogen-containing moieties, see ref. 7c,f.

(9) Chen, S.; Mercado, B. Q.; Bergman, R. G.; Ellman, J. A. J. Org. Chem. 2015, 80, 6660.

(10) Frisch, M. J.; Trucks, G. W.; Schlegel, H. B.; Scuseria, G. E.; Robb, M. A.; Cheeseman, J. R.; Scalmani, G.; Barone, V.; Mennucci, B.; Petersson, G. A.; Nakatsuji, H.; Caricato, M.; Li, X.; Hratchian, H. P.; Izmaylov, A. F.; Bloino, J.; Zheng, G.; Sonnenberg, J. L.; Hada, M.; Ehara, M.; Toyota, K.; Fukuda, R.; Hasegawa, J.; Ishida, M.; Nakajima, T.; Honda, Y.; Kitao, O.; Nakai, H.; Vreven, T.; Montgomery, J. A.; Peralta, J. E.; Ogliaro, F.; Bearpark, M.; Heyd, J. J.; Brothers, E.; Kudin, K. N.; Staroverov, V. N.; Kobayashi, R.; Normand, J.; Raghavachari, K.; Rendell, A.; Burant, J. C.; Iyengar, S. S.; Tomasi, J.; Cossi, M.; Rega, N.; Millam, J. M.; Klene, M.; Knox, J. E.; Cross, J. B.; Bakken, V.; Adamo, C.; Jaramillo, J.; Gomperts, R.; Stratmann, R. E.; Yazyev, O.; Austin, A. J.; Cammi, R.; Pomelli, C.; Ochterski, J. W.; Martin, R. L.; Morokuma, K.; Zakrzewski, V. G.; Voth, G. A.; Salvador, P.; Dannenberg, J. J.; Dapprich, S.; Daniels, A. D.; Farkas Foresman, J. B.; Ortiz, J. V.; Cioslowski, J.; Fox, D. J. Gaussian 09; Gaussian Inc: Wallingford, CT, 2009.

(11) Zhao, Y.; Truhlar, D. G. Theor. Chem. Acc. 2008, 120, 215.

(12) Marenich, A. V.; Cramer, C. J.; Truhlar, D. G. J. Phys. Chem. B 2009, 113, 6378.

(13) Legault, C. Y. CYLview, 1.0b; Université de Sherbrooke, Québec. 2009, http://www.cylview.org

(14) (a) Bach, R. D.; Glukhovtsev, M. N.; Gonzales, C.; Marquez, M.; Estevez, C. M.; Baboul, A. G.; Schlegel, H. B. J. Phys. Chem. A 1997, 101, 6092. (b) Singleton, D. A.; Merrigan, S. R.; Liu, J.; Houk, K. N. J. Am. Chem. Soc. 1997, 119, 3385. (c) Houk, K. N.; Liu, J.; DeMello, N. C.; Condroski, K. R. J. Am. Chem. Soc. 1997, 119, 10147.

(15) (a) Liu, F.; Liang, Y.; Houk, K. N. Acc. Chem. Res. 2017, 50, 2297. (b) Bickelhaupt, F. M.; Houk, K. N. Angew. Chem. Int. Ed. 2017, 56, 10070. 